\title{
Depression of Older Persons in Rural Bangladesh
}

\author{
Mohammad Abbas Uddin \\ Nursing Service, Sadar Hospital, Lakshmipur, Bangladesh \\ Email address: \\ uabbas9@gmail.com
}

\section{To cite this article:}

Mohammad Abbas Uddin. Depression of Older Persons in Rural Bangladesh. International Journal of Sustainable Development Research. Vol. 3, No. 5, 2017, pp. 47-49. doi: 10.11648/j.ijsdr.20170305.11

Received: August 27, 2017; Accepted: September 12, 2017; Published: October 28, 2017

\begin{abstract}
The proportion of older persons in Bangladesh is gradually increasing due to declining mortality rates and increased life expectancy. Bangladesh faces significant challenges around older persons' health and well-being. The aim of this study was to assess older persons' depression in two southern districts of Bangladesh and the relationship between depression and several socio-demographic characteristics. Data were collected from 280 older persons using Geriatric Depression Scale (GDS-10). Descriptive statistics were used to analyze demographic and depression data. One way classification of analysis of variance (ANOVA) was used to compare different groups of older persons with different socio-demographic characteristics. A large majority (84.3\%) of participants reported having depression. Being widowed, being illiterate, the presence of disease(s), living in a nuclear family, and having a low income were found to be significant factors contributing to older persons' depression. The identification of internal and external factors that affect older persons' depression may inform screening and intervention programs and reduce the consequences of depression.
\end{abstract}

Keywords: Bangladesh, Older Persons, Depression

\section{Introduction}

Today, many countries face the impact of ageing population. Mortality rates are declining and life expectancy is increasing. In Bangladesh, the proportion of older persons (aged 60 or above) was $6.9 \%$ in 2011 [1]. It is estimated that this will rise to $20 \%$ by 2051 [2]. With increasing life expectancy, the frequency of negative experiences among older persons increases. These may include loneliness, widowhood, death of loved ones, fear of death, and difficulty managing chronic diseases. These experiences make older persons vulnerable to depression. Compounding the issue is that depression is often under-reported by both patients and clinicians, and under-treated. As a result of these issues, depression can lead to greater levels of disability than physical sickness [3].

Depression is the changes in cognition and mood and loss of interests [4]. Depression in old age can create a number of problems, including problems in carrying out activities of daily living; increased morbidity and suicide [5], decreased physical, cognitive and social functioning; and greater selfneglect [6]. Depression is a serious public health problem in both developed and developing countries. In Bangladesh, a study found that older persons had a 2.79 times higher risk of depression that then middle-aged (40-59 years) [7]. It is important to investigate older person's depression. It is expected that this study will produce information that will help policy makers and clinicians to develop strategies for the early screening of depression and for reducing the consequences of depression for older persons.

In Bangladesh, the majority of older persons live in rural areas [8]. Typically, these areas do not provide sufficient income generation opportunities and lack adequate treatment and transportation facilities. In addition, the traditional family care system is weakening, and the frequency and quality of social interaction are decreasing. All of these factors may contribute to older persons' depression. A previous study [7], conducted in a central district near the capital city, found that female older persons with low monthly incomes were at a higher risk of depression than wealthy or high-income, middle-aged males. However, these results may not be generalizable to other districts of Bangladesh due to geographic, demographic and socioeconomic differences. The present study, therefore, 
investigates older persons' depression and its relationship to several socio-demographic characteristics in two southern districts of Bangladesh.

\section{Data and Methods}

Between September 2015 and January 2016, a descriptive study was conducted in 10 villages of two southern districts of Bangladesh. Data were collected by interviewing 280 older persons, after first confirming that they were free from cognitive impairment. A demographic data form was used, and the Geriatric Depression Scale (GDS-10) was used to measure depression [4]. This scale consists of ten items: (1) feeling satisfied with life, (2) reduction of activities, (3) feeling empty, (4) being afraid of bad things, (5) feeling happy, (6) feeling helpless, (7) memory problems, (8) feeling full of energy, (9) feeling hopeless and (10) judgment. Each item's score was either 0 (no depression) or 1 (depression). The potential total scores ranged from 0 to 10 . A total score between 0 and 4 is considered to indicate no depression and a score of 5 or more considered to indicate depression [9]. In this study, the reliability of the GDS-10 was determined by Cronbach's Alpha Coefficient. The value found was.78 and was considered satisfactory.

This secondary data were analyzed using a statistical program (SPSS 13.0). Descriptive statistics, including frequency, percentage, mean and standard deviation, were used to analyze older persons' demographic and depression data. The comparison between the two groups was carried out using one-way classification of analysis of variance (ANOVA).

\section{Results}

Table 1. Demographic Characteristics of Older Persons $(n=280)$.

\begin{tabular}{lll}
\hline Characteristics & Categories & Frequency (\%) \\
\hline \multirow{3}{*}{ Age (Mean =65.81) } & $60-65$ years & $162(57.90)$ \\
& $66-70$ years & $77(27.50)$ \\
Gender & $71-75$ years & $41(14.60)$ \\
& Male & $141(50.4)$ \\
Marital status & Female & $139(49.6)$ \\
& Married & $224(80.0)$ \\
Education level & Widow & $56(20.0)$ \\
& Illiteracy & $154(55.0)$ \\
Diseases & Literate & $126(45.0)$ \\
& No & $4(1.40)$ \\
Type of family & Yes & $276(98.60)$ \\
Family monthly income $[1$ & Nuclear & $149(53.2)$ \\
USD $=80$ Taka] & Extended & $131(46.8)$ \\
\hline
\end{tabular}

More than half $(57.90 \%)$ of older persons were between 60 and 65 years old. $50.4 \%$ were male and $49.60 \%$ were female. The majority $(80.0 \%)$ were married, and $55.0 \%$ were illiterate. Most (98.60\%) suffered from disease. 53.2\% of the sample lived in a nuclear type of family, and most (71.8\%) reported their family's monthly income as between 300 and 6,000 Taka.

Table 2. Depression of Older Persons $(n=280)$.

\begin{tabular}{lll}
\hline Variable & Categories & Frequency (\%) \\
\hline \multirow{2}{*}{ Depression } & No depression & $44(15.7)$ \\
& Having depression & $236(84.3)$ \\
\hline
\end{tabular}

The majority $(84.3 \%)$ of older persons reported having depression. Only $15.7 \%$ of the older persons reported no depression.

Table 3. Distribution of Subjects and Depression Scores with Various Socio-demographic Characteristics $(n=280)$.

\begin{tabular}{|c|c|c|c|c|c|c|c|c|}
\hline \multirow{2}{*}{ Characteristics } & \multirow{2}{*}{ Categories } & \multicolumn{2}{|c|}{ Depression score } & \multirow{2}{*}{$\begin{array}{l}\text { Sources of } \\
\text { variation }\end{array}$} & \multirow{2}{*}{$\begin{array}{l}\text { Degree of } \\
\text { freedom }\end{array}$} & \multirow{2}{*}{ Mean square } & \multirow{2}{*}{ F-value } & \multirow{2}{*}{ Sig } \\
\hline & & Mean & Standard Deviation & & & & & \\
\hline \multirow{3}{*}{ Age } & $60-65$ years & 6.70 & 2.05 & within & 2 & .25 & .063 & .939 \\
\hline & $66-70$ years & 6.71 & 1.88 & between & 277 & 3.95 & & \\
\hline & $71-75$ years & 6.59 & 1.92 & between & 271 & 3.95 & & \\
\hline \multirow{2}{*}{ Gender } & Male & 6.50 & 1.83 & within & 1 & 10.17 & \multirow{2}{*}{2.61} & \multirow{2}{*}{.107} \\
\hline & Female & 6.88 & 2.11 & between & 278 & 3.90 & & \\
\hline \multirow{2}{*}{ Marital status } & Married & 6.43 & 1.95 & within & 1 & 74.06 & \multirow{2}{*}{20.18} & \multirow{2}{*}{.000} \\
\hline & Widowed & 7.71 & 1.78 & between & 278 & 3.67 & & \\
\hline \multirow{2}{*}{ Education level } & Illiterate & 7.00 & 1.93 & within & 1 & 33.80 & \multirow{2}{*}{8.87} & \multirow{2}{*}{.003} \\
\hline & Literate & 6.30 & 1.99 & between & 278 & 3.82 & & \\
\hline \multirow{2}{*}{ Diseases } & No & 4.50 & 1.73 & within & 1 & 19.39 & \multirow{2}{*}{5.01} & \multirow{2}{*}{.026} \\
\hline & Yes & 6.72 & 1.97 & between & 278 & 3.87 & & \\
\hline \multirow{2}{*}{ Family } & Nuclear & 7.41 & 1.92 & within & 1 & 166.79 & \multirow{2}{*}{49.99} & \multirow{2}{*}{.000} \\
\hline & Extended & 5.86 & 1.72 & between & 278 & 3.33 & & \\
\hline \multirow{2}{*}{ Income (Taka) } & $3,00-6,000$ & 7.12 & 1.95 & within & 1 & 137.05 & \multirow{2}{*}{39.81} & \multirow{2}{*}{.000} \\
\hline & $6,001-20,000$ & 5.57 & 1.60 & between & 278 & 3.44 & & \\
\hline
\end{tabular}

Marital status $(\mathrm{f}=20.18, \mathrm{p}=.000)$, education level $(\mathrm{f}=$ $8.87, \mathrm{p}=.003)$, diseases $(\mathrm{f}=5.01, \mathrm{p}=.026)$, family type $(\mathrm{f}=$ $49.99, \mathrm{p}=.000)$, and income $(\mathrm{f}=39.81, \mathrm{p}=.000)$ were found to be significant factors associated to older persons' depression scores. However, age ( $\mathrm{f}=.063, \mathrm{p}=.939$ ), and gender $(f=2.61, p<.107$ ) were found to be non-significant factors on older persons' depression scores.

\section{Discussion}

The present study found that the majority of older persons reported having depression. This is consistent with the study conducted in the central district of Bangladesh [7], India [1011], and Brazil [12]. 
Being widowed was a significant factor affecting depression. This finding is consistent with a previous study's results [13], and inconsistent with another [14]. This inconsistency may be due to difference in study settings. Presence of disease(s) was also a significant factor affecting depression. This is consistent with the Indian study's results [10]. In addition, low income was a significant factor affecting depression, consistent with studies in Bangladesh [7] and India [10]. Illiteracy was another significant factor affecting depression. This is supported by a study that found that low level of education is an independent predictor of depression [15]. Furthermore, living in a nuclear family was a significant factor affecting depression. A previous study [14] also found that those living alone were more likely to suffer from depression. However, in that study, this was not statistically significant. This inconsistency may be due to differences between the study settings.

Older person's age was a non-significant factor affecting depression. This result is consistent with an Indian study [16] and inconsistent with the studies in Bangladesh [7] and India [10]. This may be due to differences in the participants' age'. Gender was also a non-significant factor of depression. This is consistent with the study conducted in India [16] and inconsistent with the Bangladesh study [7]. This inconsistency could be due to differences in study participants, including gender and age.

\section{Conclusion}

A large majority of older persons reported having depression. The significant factors that affected depression were identified as being widowed, being illiterate, suffering from disease(s), living in nuclear family, and having a low income. These results may be useful for the development of strategies for screening and treating older persons' depression in rural areas of southern Bangladesh and other areas.

\section{List of Abbreviations}

\author{
ANOVA $=$ Analysis of variance. \\ GDS $=$ Geriatric Depression Scale . \\ Taka $=$ The Bangladeshi currency $(80$ Taka $=1 \mathrm{USD})$.
}

\section{Ethical Considerations}

Permission was obtained from the district level health authority and the study participants.

\section{References}

[1] Ministry of Health and Family Welfare (Bangladesh), Health bulletin. Dhaka: Directorate General of Health Services, 2012.
[2] H. Kabir, H. T. A. Khan, M. Kabir, and M. T. Rahman, "Population ageing in Bangladesh and its implication on health care," European Scientific Journal, vol. 9, no. 33, pp. 34-47, November 2014.

[3] M. A. Oakley Browne, J. E. Wells, K. M Scott (eds). Te Rau Hinengaro: The New Zealand Mental Health Survey. Wellington: Ministry of Health, 2006.

[4] J. A. Yesavage, T. L. Brink, T. L. Rose, O. Lum, V. Huang, M. B. Adey, and V. O. Leirer. Development and validation of a geriatric depression screening scale: A preliminary report. Journal of Psychiatric Research, vol. 17, no.1, pp.37-49, 1983.

[5] R. D. Dhara, and Y. A. Jogsan. Depression and psychological well-being in old age. Journal of Psychology and Psychotherapy. vol. 3, no. 117, May 2013.

[6] D. G. Blazer. Depression in late life: Review and commentary. Journals of Gerontology. Biological Sciences and Medical Sciences. Vol.58, no. 3, pp. 249-265, March 2003.

[7] J. Das, F. D. Farzana, F. Ferdous, S. Ahmed, S. Tegenfeldt, R. C. Paul, and S. K. Das. Factors associated with elderly depression among rural Bangladeshi individuals. American Journal of Psychiatry and Neuroscience. vol. 2, no. 1, pp. 1-7, 2014.

[8] Ministry of Health and Family Welfare (Bangladesh), Health bulletin. Dhaka: Directorate General of Health Services, 2016.

[9] O. P. Almeida and S. A. Almeida. Short versions of the Geriatric Depression Scale: A study of their validity for the diagnosis of a major depressive episode according to ICD-10 and DSM-IV International Journal of Geriatric Psychiatry, vol. 14, no. 10, pp. 858-865. October 1999.

[10] P. Chauhan, P. R Kokiwar, K, Shridevi and S. Katkuri. A study on prevalence and correlates of depression among elderly population of rural South India. Int J Community Med Public Health. vol. 3, no.1, pp. 236-9, 2016.

[11] J. Vishal, R. K Bansal, S. Patel and T. Bimal. A study of depression among aged in surat city. National $\mathrm{J}$ of Community Med, vol. 1, no. 1, pp. 47-9, 2010.

[12] A. M. S. T. Assis et al. Quality of life and depressive symptoms in the elderly living in community, International Archives of Medicine, vol. 8, no. 246 pp- 1-8. 2015.

[13] S. P. Sinha, S. R. Shrivastava and J. Ramasamy. Depression in an older adult rural population in India. MEDICC Rev, vol. 15, no. 4, pp. 41-4, 2013.

[14] P. Sengupta and A. I. Benjamin. Prevalence of depression and associated risk factors among the elderly in urban and rural field practice areas of a tertiary care institution in Ludhiana. Indian J of Public Health, vol. 59, no. 1, pp. 3-8, 2015.

[15] A. M. Taqui, A. Itrat, W. Qidwai and Z. Qadri. Depression in the elderly: Does family system play a role? A cross-sectional study. BMC Psychiatry, vol. 7, no. 57, October 2007.

[16] A. P. Rajkumar, P. Thangadurai, P. Senthilkumar, K. Gayathri, M. Prince and K. S. Jacob. Nature, prevalence and factors associated with depression among the elderly in a rural south Indian community. Int Psychogeriatr, vol.21, no.2, pp. 372-8, April, 2009. 